\title{
Central Vietnam climate over the past five centuries from cypress tree rings
}

\author{
Brendan M. Buckley ${ }^{1}$ Daniel K. Stahle ${ }^{1}$ Hong Truong Luu ${ }^{2} \cdot$ S.-Y. Simon Wang ${ }^{3}$. \\ Tran Quoc Trung Nguyen ${ }^{2}$ Philip Thomas ${ }^{4}$ Canh Nam Le ${ }^{5} \cdot$ That Minh Ton $^{6}$ • \\ The Hoang Bui ${ }^{6}$ Van Thiet Nguyen ${ }^{7}$
}

Received: 27 February 2016 / Accepted: 28 June 2016

(C) Springer-Verlag Berlin Heidelberg 2016

\begin{abstract}
We present the first crossdated tree ring record from central Vietnam, derived from the growth rings of the rare cypress Fokienia hodginsii from the mountains of Quang Nam Province near the Laos border. The Quang Nam Fokienia hodginsii time series (QNFH), based on the crossdated sequences of 71 increment core samples from 37 mature trees, is the third published dendrochronological record from this species. The record extends 667 years from AD 1347 to 2013 and exhibits a mean series intercorrelation of 0.526 , similarly significant with the first two published Fokienia hodginsii records: 0.474 for Mu Cang Chai (MCFH) and 0.578 for Bidoup-Nui Ba National Park (BDFH) in the north and south of Vietnam, respectively. The Expressed Population Signal (EPS) for the QNFH
\end{abstract}

Electronic supplementary material The online version of this article (doi:10.1007/s00382-016-3297-y) contains supplementary material, which is available to authorized users.

Brendan M. Buckley

bmb@1deo.columbia.edu

1 Tree Ring Laboratory, Lamont-Doherty Earth Observatory of Columbia University, Palisades, NY 10964, USA

2 Southern Institute of Ecology, Vietnam Academy of Science and Technology, HCMC, Vietnam

3 Utah Climate Center, Utah State University, Logan, UT 84322, USA

4 International Conifer Conservation Programme of the Royal Botanic Garden, Edinburgh, Scotland, UK

5 Forest Science Institute of Central Highlands and South of Central Vietnam, Dalat City, Lam Dong Province, Vietnam

6 International Center for Tropical Highlands Ecosystems Research, Bidoup - Nui Ba National Park, Đam Rông, Lam Dong Province, Vietnam

7 Forest Science Institute of South Vietnam, HCMC, Vietnam record exceeds the generally accepted threshold of 0.85 back to AD 1567, but remains above 0.8 back to 1550 . Similar to the MCFH and BDFH records, QNFH expresses statistically significant linkages to regional hydroclimate metrics and the El Niño-Southern Oscillation. Here we present a reconstruction of the Standardized Precipitation Evapotranspiration Index for the month of April, averaged over a large region of Southeast Asia. As with prior studies we demonstrate that cool phase (La Niña) and warm phase (El Niño) events are linked to regional wet and dry conditions, respectively, with linkages to modulation of the surface water temperature over the adjacent sea to the east of Vietnam as well as the Indian Ocean. A late eighteenth century megadrought that is expressed widely across South and Southeast Asia, and notably from the MCFH and BDFH records described above, is not as pronounced in Central Vietnam and we explore the reasons why.

Keywords Vietnam · Dendrochronology $\cdot$ Cypress . Monsoon · Tropical forest $\cdot$ ENSO

\section{Introduction}

\subsection{Prior dendroclimatic research in Vietnam}

Paleo-ecological/climatological studies from the terrestrial tropics are of increasing importance, and are therefore increasingly pursued. In the case of tropical dendrochronology the previously held view that tropical trees cannot be relied upon has been replaced by an understanding that, with effort, some species can be successfully crossdated and used (e.g., Baker et al. 2005; Buckley et al. 1995, 2005, 2007a, b, 2010, 2014; D'Arrigo et al. 1997, 2011; Pumijumnong et al. 1995; Pumijumnong and Wanyaphet 2006; 
Pumijumnong and Eckstein 2011; Sano et al. 2009, 2012; Stahle et al. 2011, 2012; Therrell et al. 2006; Zuidema et al. 2013). The most robust Southeast Asian records have been developed from Fokienia hodginsii of the family Cupressaceae. Sano et al. (2009) published the first dendrochronological record of this species from $\mathrm{Mu}$ Cang Chai in the north of Vietnam (MCFH), followed by Buckley et al. (2010) from the southern limits of the species range at Bidoup-Nui Ba National Park (BDFH). Here we present the third tree-ring record from this species (QNFH) from Quang Nam Province in central Vietnam (locations shown in Fig. 1).

The Sano et al. (2009) and Buckley et al. (2010) papers are noteworthy, for they heralded the first successful attempts at passing the rigorous calibration-verification schemes used in dendroclimatology (Cook and Kairiukstis 1990) for tropical tree growth indices against instrumented climate variables. It should be noted that Fokienia hodginsii is the only species from tropical Asia that has been used successfully for climate reconstruction where it has been possible to pass calibration-verification procedures. In both cases noted above, the metric used was the Palmer Drought
Severity Index (PDSI, see Palmer 1965), and in both studies it was also shown that sea surface temperature (SST) in the classical "Niño" regions of the central equatorial Pacific were significantly, negatively correlated with the regional hydroclimatology (Fig. 2) for the beginning or "shoulder" season of the summer monsoon that extends from March to May. In general terms, warm-phase events (El Niño) correspond to regional drought in the early monsoon season as reflected by a reduction in annual radial growth of Fokienia hodginsii, while cool-phase events (La Niña) are associated with increased early monsoon moisture and enhanced annual growth. While the Asian Summer Monsoon is the main driver of rainfall for this region, ENSO's influence as described above is clearly felt.

A recent paper by Räsänen et al. (2015) demonstrates that the influence of ENSO events across Southeast Asia exhibits a great deal of spatial variability. This is particularly germane to central Vietnam and the region surrounding the current study site (QNFH), where a large percentage of the annual rainfall comes during the months that transition into the winter dry season (October to December), rather than during the peak of the summer monsoon-a

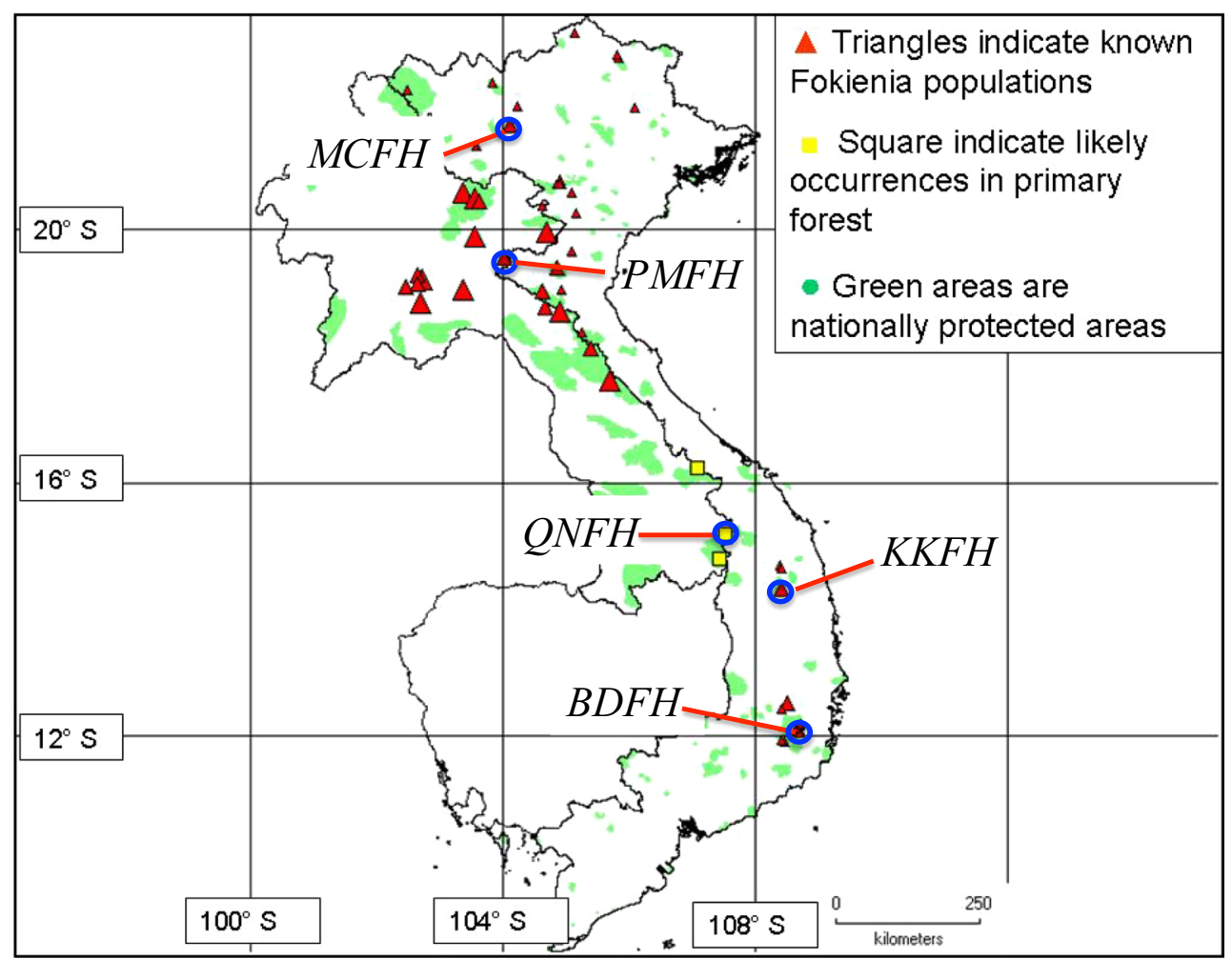

Fig. 1 Map of Indochina showing the known (red triangles) and suspected (yellow squares) stands of the rare conifer Fokienia hodginsii of the family Cupressaceae. The QNFH site (Quang Nam Fokienia hodginsii) at the center of this paper was one of the site locations projected to have this species, a projection that has been confirmed by the current study. The blue circles indicate locations where we have collected $\mathrm{Po} \mathrm{Mu}$ core samples from multiple stems, including the MCFH (Sano et al. 2009) and BDFH (Buckley et al. 2010) records referred to in the text. The PMFH (Pu Mat National Park) and KKFH (Kon Ka Kinh National Park) sites are unpublished but mostly completed with regard to crossdating and index development 
Fig. 2 The three Po Mu indices correlated against DecemberFebruary (DJF) Hadley Center sea surface temperature (SST) across the global oceans. These spatial correlation maps reveal a relationship with the classic Niño regions of the tropical Pacific that increases in strength from north to south as described in the text (all data detrended prior to correlation)



rainfall regime that is unique to this mountainous region (Li et al. 2015; Wang et al. 2015). The pattern of terrestrial rainfall in response to ENSO events for the pre-monsoon season (March-May) is, however, very robust and is evident with the instrumental records as well as with the Fokienia hodginsii growth indices as shown in Fig. 2. Buckley et al. (2010) demonstrated that the two most severe lowgrowth years in the BDFH record corresponded to the two most notorious El Niño events of the instrumental recordthe late nineteenth century Victorian Holocaust Droughts in 1877-1878 and 1888-1889, respectively (Davis 2002). The BDFH record also exhibits a very strong relationship to the Southern Oscillation Index and other measures of ENSO (Buckley et al. 2010). In fact, the ENSO signal in BDFH is robust enough to reconstruct SST over the Niño 3.4 region and pass all calibration-verification statistics, and is similarly responsive to the Interdecadal Pacific Oscillation (Buckley et al. 2010). Sano et al. (2009) found a similar response to ENSO variability for $\mathrm{MCFH}$, though not as robustly expressed as for BDFH. These correlations with ENSO for the tree ring records are consistent with the same relationships for the instrumental records from both regions (Buckley et al. 2010; Sano et al. 2009).

Another interesting feature noted for the BDFH record was the correspondence of the largest growth index years with years of high rainfall and a linkage to explosive volcanism, as noted by Buckley et al. (2010). Anchukaitis et al. (2010) demonstrated this linkage in greater detail, and they compared these findings with previous model results that did not identify a post-eruption spike in regional rainfall. Xu et al. (2011) have analysed the stable isotopes of Oxygen in the rings of Fokienia hodginsii from northern Vietnam and Laos, respectively, and demonstrate further the connection between ENSO events and the hydroclimate over Indochina. Until the current study, however, no crossdated tree growth records have been developed for the central region of Vietnam, a region with a notably different hydroclimate regime that receives a large percentage of its annual rainfall from the months of October to December as demonstrated in Fig. 3. This peak in rainfall occurs during the transition into the winter monsoon season, which is the dry season across the majority of mainland Southeast Asia 


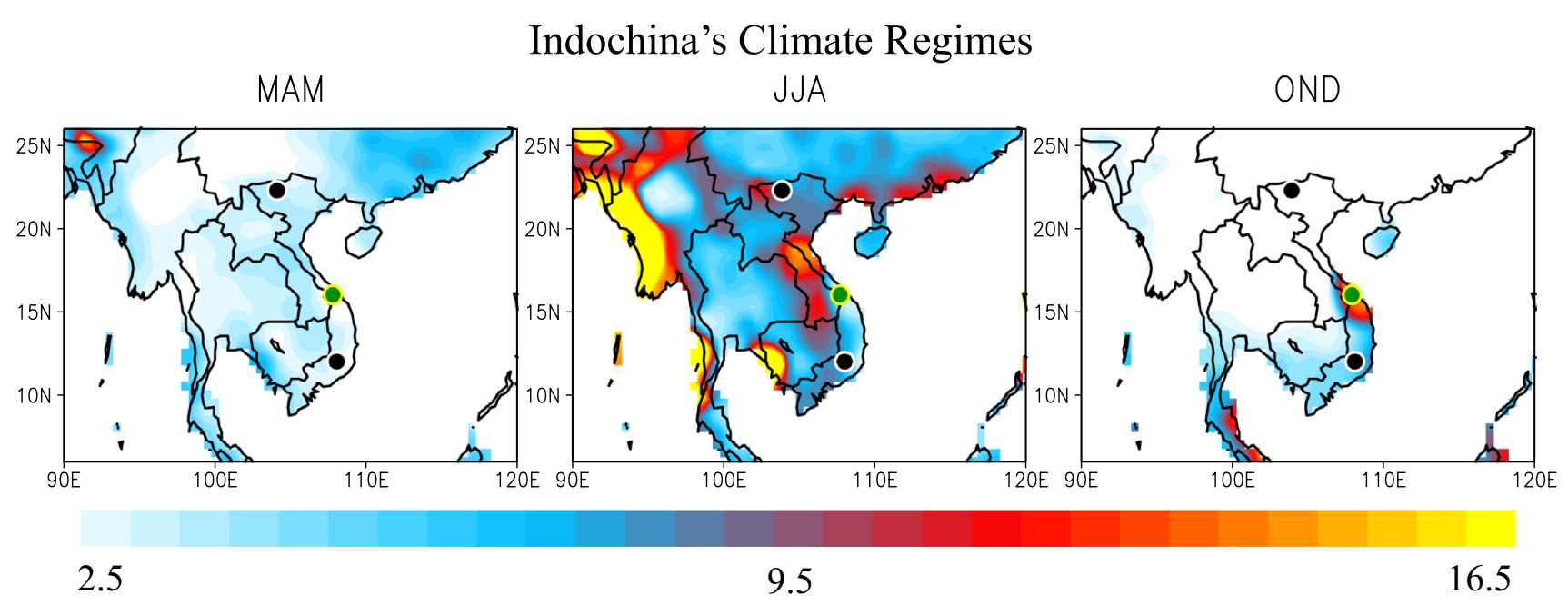

Fig. 3 Three seasonal rainfall regimes over Indochina (left MarchMay; center June-August; right October-December), and the colored circles mark the locations of the three Po Mu tree ring width records (black, top Mu Cang Chai of Sano et al. 2009; black, bottom Bidoup

including the locations of the MCFH and BDFH sites. The QNFH record that we present here serves to link the northern and southern Fokienia hodginsii sites for better regional representation and a first glimpse at the recent paleoclimate history for central Vietnam, a region that has a fundamentally different rainfall regime than regions to the north and south.

\subsection{The climate over central Vietnam}

The autumnal precipitation regime over central Vietnam is associated with an increase in the occurrence of tropical cyclones (TCs) that pose a significant threat to lives and property, making the region particularly vulnerable to the effects of climate change (McElwee 2012). Li et al. (2015) identified and analyzed a pronounced decadal oscillation of autumn precipitation in central Vietnam within the $8-11$ years frequency band that is modulated by the East Pacific-North Pacific (EP-NP) teleconnection, an ENSO-like variability at lower frequency. The negative phase of the EP-NP pattern is associated with a positive SST anomaly in the semi-closed sea east of Vietnam (commonly referred to as the South China Sea, but in Vietnam it is referred to as the East Sea) that induces low-level convergence, enhances convection, and increases precipitation over Central Vietnam and adjacent Hainan Island (China) and the Philippines. This circulation feature is embedded in the large-scale circulation associated with SST anomalies across the Pacific Ocean, where cooling in the Eastern and Central tropical Pacific is sandwiched between warm anomalies in the North and South Pacific and a warm Western Pacific Ocean. The positive phase of the
Nui Ba of Buckley et al. 2010; and green Quang Nam from the current study). Rainfall data from NOAA PREC/L data set for the period 1948 to present (Chen et al. 2002)

EP-NP features opposite SST and circulation anomalies and reduced rainfall over central Vietnam ( $\mathrm{Li}$ et al. 2015). Warming SST and enhanced southerly low-level winds coincide with increased rainfall and TCs, and are part of a hemispheric-scale change in the general circulation in the form of a La Niña-like SST anomaly and a strengthened Walker circulation branch that ascends near Vietnam and the far-western Pacific (Wang et al. 2015).

Central Vietnam's spring climate (i.e., March-May) is the so-called "shoulder" season of the monsoon cycle where the ITCZ begins its annual migration into the Northern Hemisphere. The change across Indochina is dramatic with the influx of moisture and high maximum temperature replacing the cool nights and low humidity of the winter dry season. This season has been shown in previous dendroclimatic studies using conifers from tropical Asia (e.g., Buckley et al. 1995, 2005, 2010; Sano et al. 2009) to exert the greatest influence on annual radial growth. As we note above (and show in Fig. 3), the central portion of Vietnam enters this transitional season with a potential reduction in soil moisture deficit compared with regions to the north and south, owing to the late-season spike in rainfall from October to December that is unique to central Vietnam.

\section{Materials and methods}

\subsection{The study location}

We sampled living Fokienia hodginsii trees from Tay Giang Protection Forest in central Vietnam's Quang Nam Province, a location that was until recently only suspected 
Table 1 Common angiosperm forest species that coexist with Fokienia hodginsii at our study site in Tay Giang Protection Forest, Quang Nam Province, Vietnam

\begin{tabular}{|c|c|c|c|}
\hline Factor & Family & Genus & Species \\
\hline \multirow[t]{9}{*}{ Canopy dominant } & Fagaceae & Castanopsis & spp. \\
\hline & & Lithocarpus & spp. \\
\hline & & Quercus & spp. \\
\hline & Lauraceae & Cinnamomum & spp. \\
\hline & & Litsea & spp. \\
\hline & Magnoliaceae & Magnolia & spp. \\
\hline & Theaceae & Anneslea & fragrans \\
\hline & & Polyspora & spp. \\
\hline & & Schima & wallichii \\
\hline \multirow[t]{13}{*}{ Below canopy } & Annonaceae & Polyalthia & spp. \\
\hline & Asparagaceae & Dracaena & spp. \\
\hline & Euphorbiaceae & Multiple & Multiple \\
\hline & Melastomataceae & Melastoma & spp. \\
\hline & & Sonerila & spp. \\
\hline & Lauraceae & Cinnaтотит & spp. \\
\hline & & Litsea & spp. \\
\hline & Moraceae & Ficus & spp. \\
\hline & Primulaceae & Ardisia & spp. \\
\hline & Rubiaceae & Ixora & spp. \\
\hline & & Lasianthus & spp. \\
\hline & Rutaceae & Clausena & spp. \\
\hline & & Glycomis & spp. \\
\hline \multirow[t]{12}{*}{ Herbaceous layer } & Araceae & Arisaema & sp. \\
\hline & Asparagaceae & Peliosanthes & cf. teta \\
\hline & Balsaminaceae & Impatiens & sp. \\
\hline & Cyperaceae & Cyperus & leucocephalus \\
\hline & Orchidaceae & Multiple & Multiple \\
\hline & Piperaceae & Piper & spp. \\
\hline & Poaceae & Bambusa & cf. balcooa \\
\hline & & Panicum & notatum \\
\hline & Xanthorrhoeaceae & Dianella & ensifolia \\
\hline & Zingiberaceae & Атотит & spp. \\
\hline & & Globba & spp. \\
\hline & & Zingiber & spp. \\
\hline
\end{tabular}

of containing Fokienia hodginsii. Our study confirms the existence of old growth Fokienia hodginsii on variable terrain between 1200 and 1500 meters above mean sea level, amongst what appears as a virtually undisturbed mixed evergreen broadleaved-coniferous forest growing over a humus layer up to $1 \mathrm{~m}$ thick. We observed very few signs of human disturbance (e.g., stumps, clearings, etc.), and the fact that such a large and old-aged population of Fokienia hodginsii remains in this forest is itself evidence for lack of disturbance, since these trees are highly prized and logged over its entire distribution range. Furthermore, the local Co Tu minority group protects this forest as a local "spirit forest", due to Fokienia's history as the wood most sought after for use as coffins by their ancestors. Of the five conifer species found at this site Fokienia hodginsii, Dacrycarpus imbricatus, Dacrydium elatum and Nageia wallichiana are canopy emergent, while Podocarpus neriifolius comprises a less dominant role in the understory. With the exception of Fokienia hodginsii, all of these conifer species are members of the predominantly Southern Hemisphere conifer family Podocarpaceae. We also identified multiple broadleaf species at this site, notably from the canopy dominant families of Magnoliaceae, Fagaceae, Lauraceae and Theaceae (see Table 1 for a full listing of angiosperms we identified at the study site).

\subsection{Vietnamese cypress increment cores}

During January 2014 we obtained 112 core samples from 45 mature Fokienia hodginsii stems from the Tay Giang Protection Forest (see Fig. 1). We used Haglof increment borers to extract $5 \mathrm{~mm}$ diameter dowels of wood that extend from the bark to as near the center of each tree as possible, and from at least two sides of each stem. Every cored tree was georeferenced with GPS, and all core samples were placed into labeled plastic straw tubes for transport from the forest to the laboratory. Once in the laboratory, all samples were air-dried and then glued into wooden core mounts with their transverse surface exposed. Each core was then surfaced using progressively finer sandpaper and micromesh abrasives in order to reveal the cellular structure of the growth rings, essential for identification of true ring boundaries and occurrences of "false" rings and other anatomical features (Fritts 1976).

\subsection{Crossdating, measuring and quality control}

The surfaced cores were analyzed under microscopy at low magnification $(7 \times-40 \times)$ and were crossdated visually with the aid of the skeleton plotting method (Stokes and Smiley 1968; Fritts 1976). This proved to be a crucial step for all ensuing analyses due to the complex ring anatomy and growth irregularities (Fig. 4) that made crossdating difficult in these cores. The absolute dating of growth rings in trees is arguably the most important step in dendrochronology, since without ensuring correct dates for every single ring in sequence, cumulative error is built into the final time series as demonstrated by Fritts and Swetnam (1989) and more recently by Black et al. (2016). In the case of sites where locally absent rings and "false" rings are minimal, the error might be marginally consequential to ensuing climate analyses. However, in the case of tropical trees and the Fokienia hodginsii from QNFH in particular, a plethora of such problem rings would result in significant error. For example, within our final subset of retained cores 61 of the 



Fig. 4 Problematic rings in $\mathrm{Po} \mathrm{Mu}$ cores from a site nearby to QNFH. Clockwise from the top, core MB03B shows an injury where three rings in succession (1607-1609) are locally absent as indicated by the offset red dots and the letters MR (missing ring). The two vertical sections on the right for cores MB53B and MB46B show great examples of tricky "false" rings, an MR in the year 1594, and high

22,662 rings analyzed were locally absent $(0.27 \%)$, and there are numerous examples of false rings that challenged our abilities to accurately identify them (examples shown in Fig. 4). Consequently, there were several cores that we were not able to confidently crossdate and these were excluded from further analyses.

Following the rigorous crossdating procedure described above, 71 cores from 37 trees were included in our final ring width index (see Table 2). We compared our QNFH master index to the BDFH record (Buckley et al. 2010), which is from a location several $100 \mathrm{~km}$ to the south (see Fig. 1). The two site collections do share some key narrow "marker" growth years (i.e., 2005, 1978, 1889, 1804, 1692, and 1565 ), as well as many key wide growth years (i.e., 1976, 1875, 1835, 1767, and 1645), and similar comparisons were made with the MCFH site from northern Vietnam. While similarities of key years can be seen between all three sites, several marker years are unique to each site, and significant differences in the low frequency components of these records are clearly expressed. As discussed variability in ring width. On the bottom left cores MB53C (bottom) and MB53B (top) show that even from the same tree, growth rings can often be missing on one radius but not the other. Only through rigorous crossdating using skeleton plotting and other methods are these problems resolvable

later in this paper, these expressed differences in tree growth are consistent with the variability of regional climate from the different climate regions of Indochina.

\subsection{Indexing radial growth through time}

Tree ring standardization aims to remove what is commonly referred to as the "biological growth trend", but is actually the result of stem geometry (i.e., adding approximately the same volume of wood annually to a circumference that increases with each annual increment results in an hypothetical negative exponential decay of the width of rings through time). A second aim is to stabilize the time series variance from juvenile to maturity phases, an issue that is related to the biological growth trend (Fritts 1976; Cook and Kairiukstis 1990). For the current study we employed the relatively new method of "signal-free" standardization (SFS), first developed by Melvin and Briffa (2008) and expanded upon by Briffa and Melvin (2011) and most recently Melvin and Briffa (2014). Here we utilized program RCSigFree, 
Table 2 Details of the QNFH tree ring samples, showing the ID tag for each included tree, the number of cores from each tree that was included in the final indexed record, the first and last years measured (YOM), the number of locally absent rings in each tree (LAB) and the correlation of each tree with the master index (averaged between the total number of cores for each tree)

\begin{tabular}{|c|c|c|c|c|c|}
\hline Tree ID & No. cores & 1st YOM & Last YOM & No. LAB & Corr. master \\
\hline TGFH02 & 1 & 1628 & 1740 & 0 & 0.434 \\
\hline TGFH03 & 2 & 1600 & 2010 & 7 & 0.578 \\
\hline TGFH04 & 3 & 1588 & 2013 & 2 & 0.528 \\
\hline TGFH06 & 2 & 1570 & 1800 & 0 & 0.431 \\
\hline TGFH07 & 2 & 1588 & 2013 & 1 & 0.605 \\
\hline TGFH08 & 2 & 1560 & 2006 & 0 & 0.455 \\
\hline TGFH09 & 2 & 1550 & 2013 & 0 & 0.482 \\
\hline TGFH10 & 3 & 1550 & 2013 & 5 & 0.533 \\
\hline TGFH11 & 3 & 1600 & 2013 & 3 & 0.563 \\
\hline TGFH13 & 3 & 1347 & 1970 & 1 & 0.521 \\
\hline TGFH15 & 3 & 1568 & 2013 & 0 & 0.507 \\
\hline TGFH16 & 2 & 1560 & 1750 & 1 & 0.431 \\
\hline TGFH17 & 2 & 1550 & 1808 & 0 & 0.462 \\
\hline TGFH19 & 1 & 1600 & 1900 & 0 & 0.453 \\
\hline TGFH21 & 2 & 1645 & 2012 & 3 & 0.538 \\
\hline TGFH23 & 1 & 1575 & 2011 & 0 & 0.458 \\
\hline TGFH25 & 1 & 1600 & 2013 & 1 & 0.525 \\
\hline TGFH26 & 2 & 1680 & 2013 & 4 & 0.521 \\
\hline TGFH29 & 3 & 1573 & 2013 & 5 & 0.495 \\
\hline TGFH30 & 1 & 1764 & 2013 & 1 & 0.450 \\
\hline TGFH33 & 2 & 1520 & 1940 & 2 & 0.421 \\
\hline TGFH35 & 3 & 1582 & 2013 & 12 & 0.521 \\
\hline TGFH37 & 1 & 1600 & 1680 & 0 & 0.410 \\
\hline TGFH42 & 1 & 1750 & 2013 & 0 & 0.506 \\
\hline TGFH43 & 3 & 1680 & 2013 & 9 & 0.582 \\
\hline TGFH44 & 2 & 1520 & 2013 & 0 & 0.553 \\
\hline TGFH45 & 2 & 1601 & 2013 & 0 & 0.524 \\
\hline TGFH46 & 1 & 1567 & 2013 & 0 & 0.537 \\
\hline TGFH47 & 1 & 1594 & 2013 & 1 & 0.448 \\
\hline TGFH48 & 1 & 1800 & 2013 & 0 & 0.495 \\
\hline TGFH52 & 1 & 1870 & 2013 & 0 & 0.486 \\
\hline TGFH54 & 1 & 1644 & 1950 & 0 & 0.577 \\
\hline TGFH56 & 2 & 1561 & 1800 & 0 & 0.464 \\
\hline TGFH57 & 3 & 1600 & 2013 & 3 & 0.562 \\
\hline TGFH58 & 1 & 1640 & 2013 & 0 & 0.449 \\
\hline TGFH59 & 3 & 1532 & 2013 & 0 & 0.638 \\
\hline TGFH60 & 2 & 1700 & 1959 & 0 & 0.584 \\
\hline
\end{tabular}

software developed at the Lamont-Doherty Earth Observatory's Tree Ring Lab (http://www.ldeo.columbia.edu/ tree-ring-laboratory/resources/software) as a way to correct for trend distortion effects at the ends of series that are caused by the fitted growth curves. A prime example of such distortion can be seen from the positive trend in tree growth from many upper elevational and latitudinal treeline locations over the twentieth century that is associated with positive temperature trends (Melvin and Briffa 2008). The SFS method is able to preserve the resolvable medium to low frequency variance that is common to the sampled trees (assumed to result from climate's influence on radial growth), while removing similar time scales of variability among the sampled trees that is not shared (resulting from endogenous forest effects). We include additional text with output files and graphics of our implementation of the SFS method in the Supplemental Online Materials.

\subsection{Climate data}

We compared the QNFH indices with a variety of climatic data, focusing initially on the same parameters shown by Sano et al. (2009) and Buckley et al. (2010) to be most strongly correlated with the annual growth of Fokienia hodginsii (i.e., the Palmer Drought Severity Index or PDSI from Dai et al. 2004; and global SST fields from the Hadley Center in the UK). We also utilized the Standardized Precipitation Evapotranspiration Index (SPEI) obtained from the Global SPEI database (http://sac.csic.es/spei/database. html; Trouet and Van Oldenborgh 2013). The SPEI data are derived from the Climate Research Unit (University of East Anglia, U.K.) dataset of monthly precipitation and evapotranspiration (CRU TS), which has a spatial resolution of 0.5 degrees. Vicente-Serrano et al. (2010) first presented SPEI as an improvement over PDSI as a drought metric in the tropics for studying the effects of global warming on drought severity. As with PDSI, SPEI considers the effect of evapotranspiration on the severity of drought, however SPEI is better suited to a broader set of ecosystems due to its multi-scalar nature, its sensitivity to evapotranspiration demand and its simplicity of calculation (Begueria et al. 2014; Vicente-Serrano et al. 2010, 2013). We therefore elected to pursue SPEI averaged over a 1-month window as our target for reconstruction for this region, rather than PDSI. For analysis, we used the web-based KNMI Climate Explorer (http://climexp.knmi.nl/) for doing basic statistical correlation and regression analyses, as well as statistical packages developed at the Tree Ring Lab of the LamontDoherty Earth Observatory such as Principal Components Regression analyses for reconstruction of climate from tree rings.

\section{Results and discussion}

\subsection{Indexed growth at Quang Nam}

The stabilized SFS-derived indices of Fokienia hodginsii growth at Quang Nam in central Vietnam are presented in 
Fig. 5. The fidelity of the common signal at this site is exemplified by an overall series intercorrelation of 0.526 , similar to values obtained for MCFH (0.474) and BDFH (0.578), and an EPS value that exceeds the accepted threshold of 0.85 (Wigley et al. 1984) from 1567 out to the present, and exceeds 0.80 from 1550 (see Figure S4). QNFH exhibits several periods of above and below average growth over the past five centuries, including a decadal scale low-growth departure at the beginning of the twentieth century that is bracketed by two periods of above average growth from about 1860-1890 and from 1920 to 1950 , respectively. Another high growth period is evident during the mid seventeenth century. The decadalscale low growth of the latter eighteenth century that is visible across all of Southeast Asia in prior studies (e.g., Buckley et al. 2007b, 2010, 2014; Cook et al. 2010; D'Arrigo et al. 2011; Sano et al. 2009) appears to be less evident for QNFH, and we contend that this may be the result of the influence of the autumnal rainfall regime that is unique to central Vietnam (see Fig. 3). We propose that this source of moisture may serve to mitigate the effect of soil moisture deficit that is felt during the subsequent annual dry season, relative to regions to the north and south. In addition, two of the most negative marker years of at BDFH, 1877 and 1889, which reflect the influence of the ENSO-driven late nineteenth century Victorian Holocaust Droughts (Davis 2002), are not evident in QNFH. This difference may reflect the modulating effects of local and Indian Ocean SST anomalies as will be discussed in the later part of Sect. 3.2.

For each of the three Fokienia hodginsii records there are periods that are in and out of phase, and it is evident from the 51-year running correlation analyses shown in Fig. 6 that systematic offsets occur between all three regions. Notably, the latter half of the eighteenth century during the worst of the Strange Parallels Drought (Cook et al. 2010) is a period of strong agreement between the $\mathrm{MCFH}$ and BDFH sites, both of which are poorly correlated with QNFH at this time. This suggests that the decadal scale effects of the Strange Parallels Drought were felt more acutely in the northern and southern regions than they were at $\mathrm{QNFH}$, with the central portion

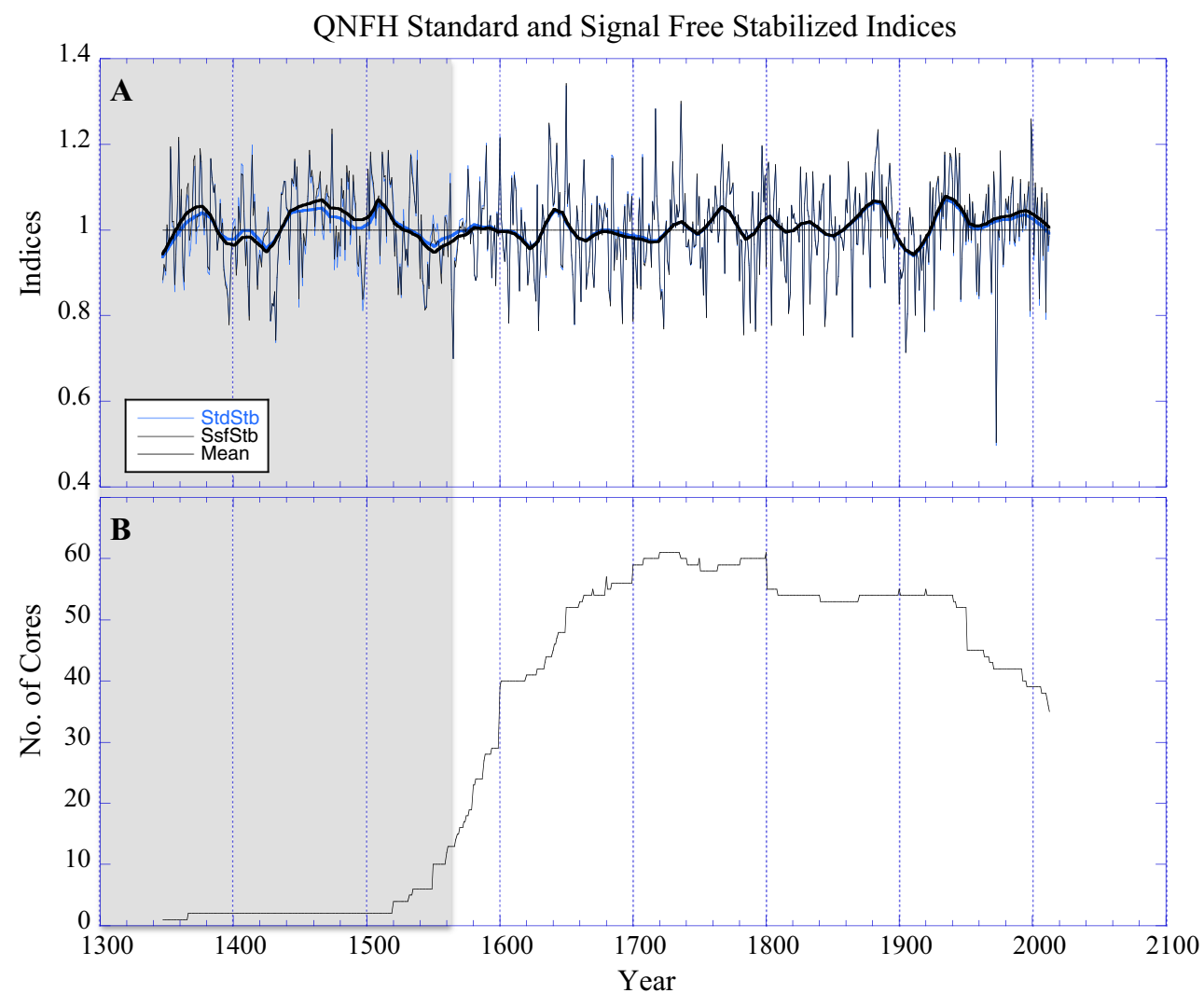

Fig. 5 The QNFH growth indices from 1350 to 2013 derived from the Signal Free Standardization method of Melvin and Briffa (2008) after variance stabilization, and the sample depth (no. of cores) through time in the lower plot $\mathrm{B}$. The gray box indicates the period before 1567 where EPS is $<0.85$ (EPS exceeds 0.80 from 1550). The blue and black lines in A show the Standard and Signal Free indices, respectively. For complete details see Table 3 and the Supplementary Online Material 


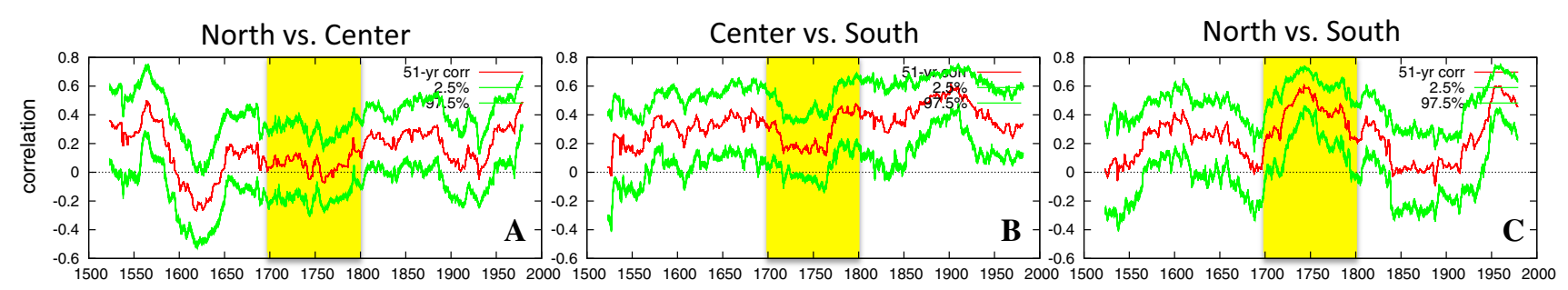

Fig. 6 Running 51-year correlation plots of the three Po Mu tree ring indices against each other from $\mathrm{AD} 1500$ to the most recent years in common (2004, 2007 for MCFH in the north and BDFH in the south, respectively). The yellow bars highlight the eighteenth century where the correlation is strongest between $\mathrm{MCFH}$ and BDFH (c) and weakest between MCFH and QNFH (a), and weak relative the remainder of the record for QNFH and BDFH (b), where it is noteworthy that the general trend in correlation increases through time. Also of note is the early half of the seventeenth century where north and central Vietnam appear to be out of phase (a) while north and south are more strongly in agreement (c) of Vietnam showing far less persistent drought for the important "shoulder" monsoon season in April. Räsänen et al. (2015, Fig. 2) suggests that the boundary of the wet/dry influence of warm phase ENSO events for winter (DJF) as measured from the Multivariate ENSO Index (MEI) falls very near to QNFH, just to the northeast along the Hai Van Pass-a well-known climatic boundary in Central Vietnam at around $16^{\circ}$ North latitude (e.g., Ho et al. 2011). According to Li et al. (2015) and Wang et al. (2015), local SST in the Sea between Vietnam and the Philippines and farther east over the Philippine Sea also modulate climate over Indochina, adding another source of variability in addition to ENSO. It is plausible that changes in the mean position of this boundary may influence the soil moisture conditions antecedent to the onset of the summer monsoon, a subject worthy of further study.

\subsection{Climate-growth relationships}

The relationship between QNFH and PDSI, while consistent with prior results from MCFH and BDFH, is more weakly expressed as shown in the left hand panels of Fig. 7. While Sano et al. (2009) and Buckley et al. (2010) were able to generate robust reconstructions of pre-monsoon PDSI (March-May) from their respective Fokienia hodginsii records, the relationship for QNFH is not strong enough to allow for robust statistical reconstruction of this metric. However, as shown in the right hand panels of Fig. 7, the relationship with the SPEI for the month of April stands out as a month of significant correlation for the QNFH site with a large swath over mainland Southeast Asia. We averaged together the gridded April SPEI measurements from the two regions that are outlined by the black boxes shown in panel (e) from Fig. 7 (data shown in Fig. 8) and used this as our target

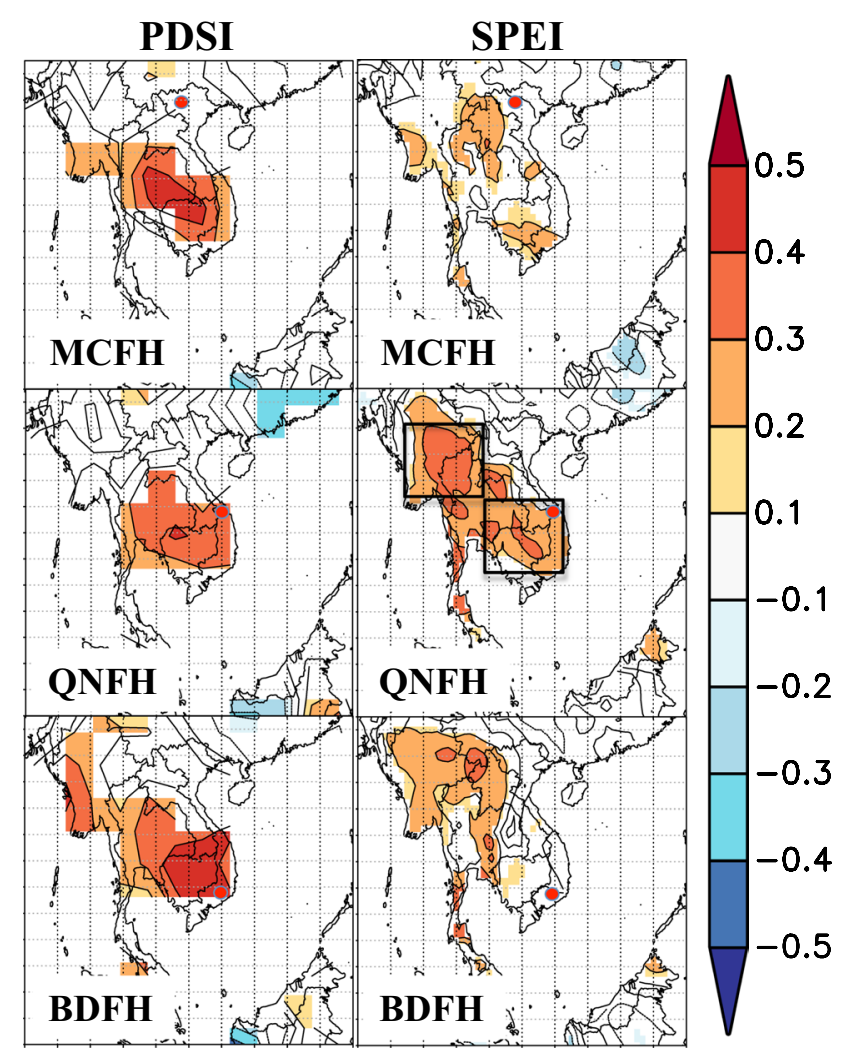

Fig. 7 Correlation fields between MCFH, QNFH and BDFH with (left) UCAR scPDSI and (right) SPEI 1 month average from the Global Drought Monitor (http://sac.csic.es/spei/index.html). Tree ring comparisons are made for the period of 1901 (SPEI) and 1950 (PDSI) to the outer year of each record (2004, 2013 and 2007, respectively). For PDSI the 3-month season of March-May was used for MCFH and BDFH, and April-June for QNFH which shows the highest level of significance. For SPEI we show correlation with April SPEI for MCFH and QNFH and May for BDFH, to illustrate the most significant months of correlation at each site. The red dots indicate the locations of each tree ring site, and the two black boxes show the regions of April SPEI used for reconstruction by QNFH as described in the text 


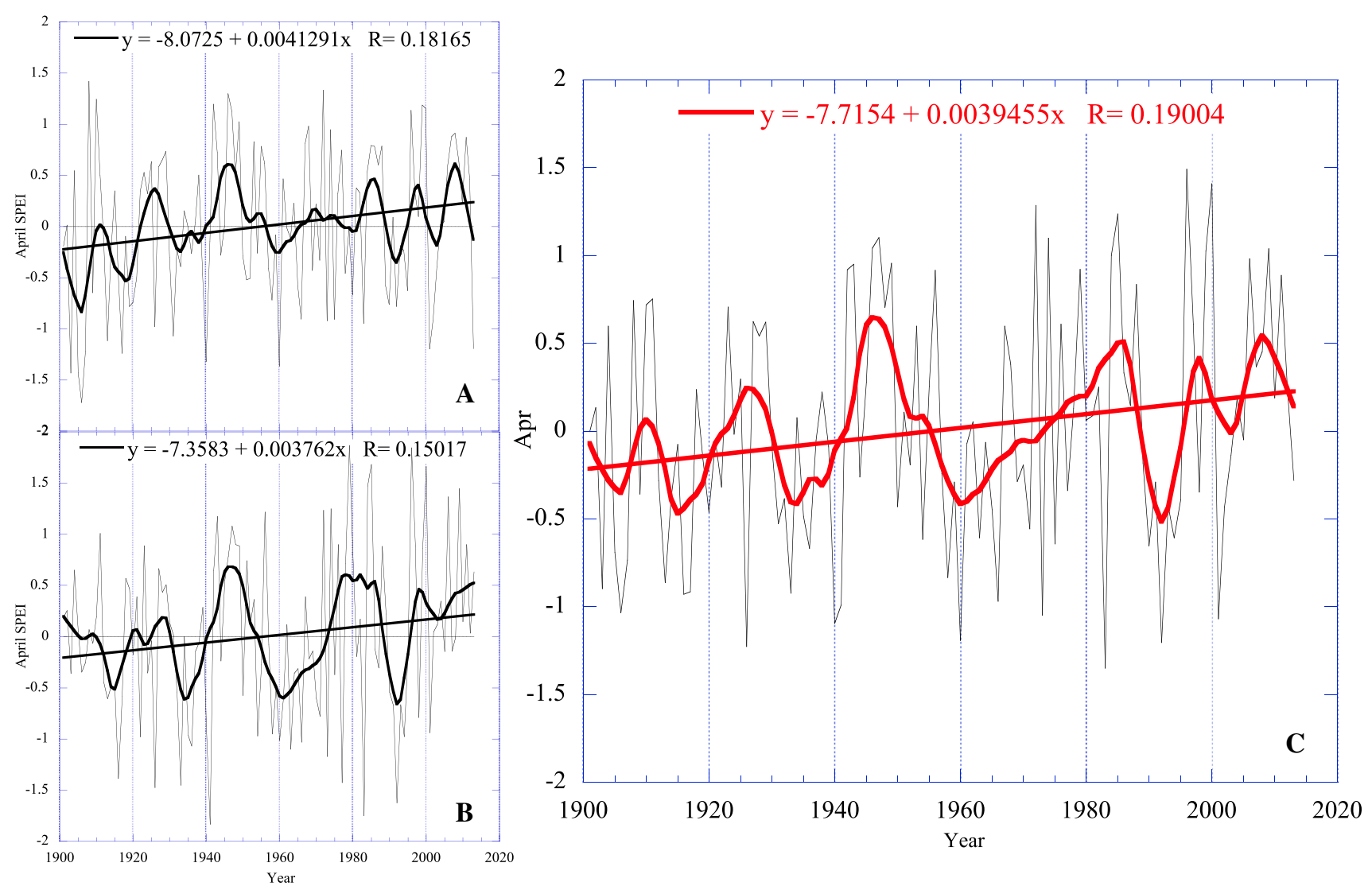

Fig. 8 April SPEI for a upper box, b lower box, and $\mathbf{c}$ the average of two boxes shown in Fig. 7. The correlation between the two boxes is 0.51. Data derived from the SPEI Global Drought Monitor (http://sac.csic.es/spei/map/maps.html)

metric for reconstruction. The result is a successfully calibrated and verified reconstruction model (Table 3) and a reconstruction of April SPEI over mainland Southeast Asia that is plotted in Fig. 9, and explains $23.3 \%$ of the overall variance of the target dataset. While this value may seem somewhat low, the model passes all verification tests when using either half of the record for calibration (Table 3). This is particularly the case with regard to first differenced data, which indicates a high degree of year-to-year variance in common. The coefficient of efficiency statistic (CE) for verification on both halves of the record is consistently positive, and therefore indicates an acceptable amount of model fidelity (Cook and Kairiukstis 1990).

For comparison purposes, a plot of all three Vietnam tree-ring based climate reconstructions, from north to south, is presented in Fig. 10. The gray shaded boxes within each panel of this plot indicates the period of less confidence based on the EPS, thus limiting our earliest years of comparison to 1650,1567 and 1250 C.E., respectively. While the response of QNFH to SST over the classic "Niño" regions of the tropical Pacific is similar to that for MCFH and BDFH (Fig. 2), the correlation fields are weaker. A look at the relationship between reconstructed April SPEI and temperature at the surface, at the $850 \mathrm{mb}$ height and at the $200 \mathrm{mb}$ height (Fig. 11) reveals an apparent inverse relationship between SPEI and temperature over the equatorial zone and the primary areas of ENSO activity in the Pacific, accompanied by an even stronger upper atmospheric La Niña pattern with its accompanying equatorial low-pressure anomalies. An equally strong direct correlation with temperature over the high-elevation of the Tibetan Plateau and most of Eurasia reflects the anomalously strong thermal gradient that develops during the buildup of the annual monsoon that typically forms during La Niña 
Table 3 April SPEI

reconstruction model results for late calibration (1951-2013 top two tables) and early calibration (1901-1950 bottom two tables) in the left hand columns, and for verification periods as denoted by the (v) in the 3 right hand columns

\begin{tabular}{|c|c|c|c|c|c|c|}
\hline Test & Score & T stat & Prob. & Score $(v)$ & T-stat (v) & Prob. (v) \\
\hline \multicolumn{7}{|c|}{ Undifferenced late calibration (1951-2013) Verification (1901-1950) } \\
\hline Equality of means & 0.000 & 0.000 & 0.996 & -0.094 & -0.920 & 0.639 \\
\hline Cross products mean & 0.145 & 3.041 & 0.002 & 0.045 & 0.953 & 0.326 \\
\hline Sign test & $41+22-$ & $2.268^{*}$ & 0.012 & $34+16-$ & $2.404 *$ & 0.008 \\
\hline Pearson correlation & $r=0.483$ & 4.311 & 0.000 & $r=0.369$ & 2.753 & 0.004 \\
\hline Robust correlation & $r=0.447$ & 3.904 & 0.000 & $r=0.419$ & 3.200 & 0.001 \\
\hline Spearman correlation & $\mathrm{r}=0.483$ & 4.304 & 0.000 & $r=0.389$ & 2.927 & 0.003 \\
\hline Kendall Tau & $\mathrm{t}=0.344$ & $3.982 *$ & 0.000 & $\mathrm{t}=0.272$ & $2.785^{*}$ & 0.003 \\
\hline Reduction of error & 0.233 & & & 0.137 & & \\
\hline Coefficient of efficiency & 0.233 & & & 0.106 & & \\
\hline Test & Score & T stat & Prob. & Score (v) & T-stat (v) & Prob. (v) \\
\hline \multicolumn{7}{|c|}{ First differenced late calibration (1951-2013) verification (1901-1950) } \\
\hline Equality of means & -0.004 & -0.029 & 0.975 & -0.008 & -0.060 & 0.951 \\
\hline Cross products mean & 0.506 & 3.700 & 0.000 & 0.215 & 2.222 & 0.015 \\
\hline Sign test & $41+21-$ & $2.413 *$ & 0.008 & $32+17-$ & $2.000^{*}$ & 0.023 \\
\hline Pearson correlation & $r=0.659$ & 6.779 & 0.000 & $\mathrm{r}=0.493$ & 3.889 & 0.000 \\
\hline Robust correlation & $r=0.625$ & 6.204 & 0.000 & $r=0.525$ & 4.227 & 0.000 \\
\hline Spearman correlation & $r=0.658$ & 6.760 & 0.000 & $\mathrm{r}=0.481$ & 3.766 & 0.000 \\
\hline Kendall Tau & $\mathrm{t}=0.479$ & $5.497 *$ & 0.000 & $\mathrm{t}=0.344$ & $3.482^{*}$ & 0.000 \\
\hline Reduction of error & 0.424 & & & 0.241 & & \\
\hline Coefficient of efficiency & 0.424 & & & 0.241 & & \\
\hline Test & Score & T stat & Prob. & Score $(v)$ & T-stat (v) & Prob. (v) \\
\hline \multicolumn{7}{|c|}{ Undifferenced early calibration (1901-1950) verification (1951-2013) } \\
\hline Equality of means & 0.000 & 0.000 & 1.000 & 0.100 & 1.060 & 0.289 \\
\hline Cross products mean & 0.060 & 1.588 & 0.057 & 0.087 & 2.344 & 0.011 \\
\hline Sign test & $32+18-$ & $1.838^{*}$ & 0.033 & $45+18-$ & 3.276 & 0.001 \\
\hline Pearson correlation & $\mathrm{r}=0.369$ & 2.753 & 0.004 & $r=0.483$ & 4.311 & 0.000 \\
\hline Robust correlation & $\mathrm{r}=0.419$ & 3.200 & 0.001 & $\mathrm{r}=0.447$ & 3.904 & 0.000 \\
\hline Spearman correlation & $\mathrm{r}=0.389$ & 2.927 & 0.003 & $r=0.483$ & 4.304 & 0.000 \\
\hline Kendall Tau & $\mathrm{t}=0.272$ & $2.785^{*}$ & 0.003 & $\mathrm{t}=0.344$ & 3.982 & 0.000 \\
\hline Reduction of error & 0.136 & & & 0.227 & & \\
\hline Coefficient of efficiency & 0.136 & & & 0.203 & & \\
\hline Test & Score & T stat & Prob. & Score (v) & T-stat (v) & Prob. (v) \\
\hline \multicolumn{7}{|c|}{ First differenced early calibration (1901-1950) verification (1951-2013) } \\
\hline Equality of means & -0.008 & -0.063 & 0.948 & -0.005 & -0.034 & 0.972 \\
\hline Cross products mean & 0.170 & 2.220 & 0.015 & 0.401 & 3.700 & 0.000 \\
\hline Sign test & $32+17-$ & 2.000 & 0.023 & $41+21-$ & 2.413 & 0.008 \\
\hline Pearson correlation & $\mathrm{r}=0.493$ & 3.889 & 0.000 & $\mathrm{r}=0.659$ & 6.779 & 0.000 \\
\hline Robust correlation & $\mathrm{r}=0.525$ & 4.227 & 0.000 & $r=0.625$ & 6.204 & 0.000 \\
\hline Spearman correlation & $\mathrm{r}=0.481$ & 3.766 & 0.000 & $r=0.658$ & 6.760 & 0.000 \\
\hline Kendall Tau & $\mathrm{t}=0.344$ & 3.482 & 0.000 & $\mathrm{t}=0.479$ & 5.497 & 0.000 \\
\hline Reduction of error & 0.239 & & & 0.387 & & \\
\hline Coefficient of efficiency & 0.239 & & & 0.387 & & \\
\hline
\end{tabular}

* Denotes z scores for Sign test and Kendall Tau tests 

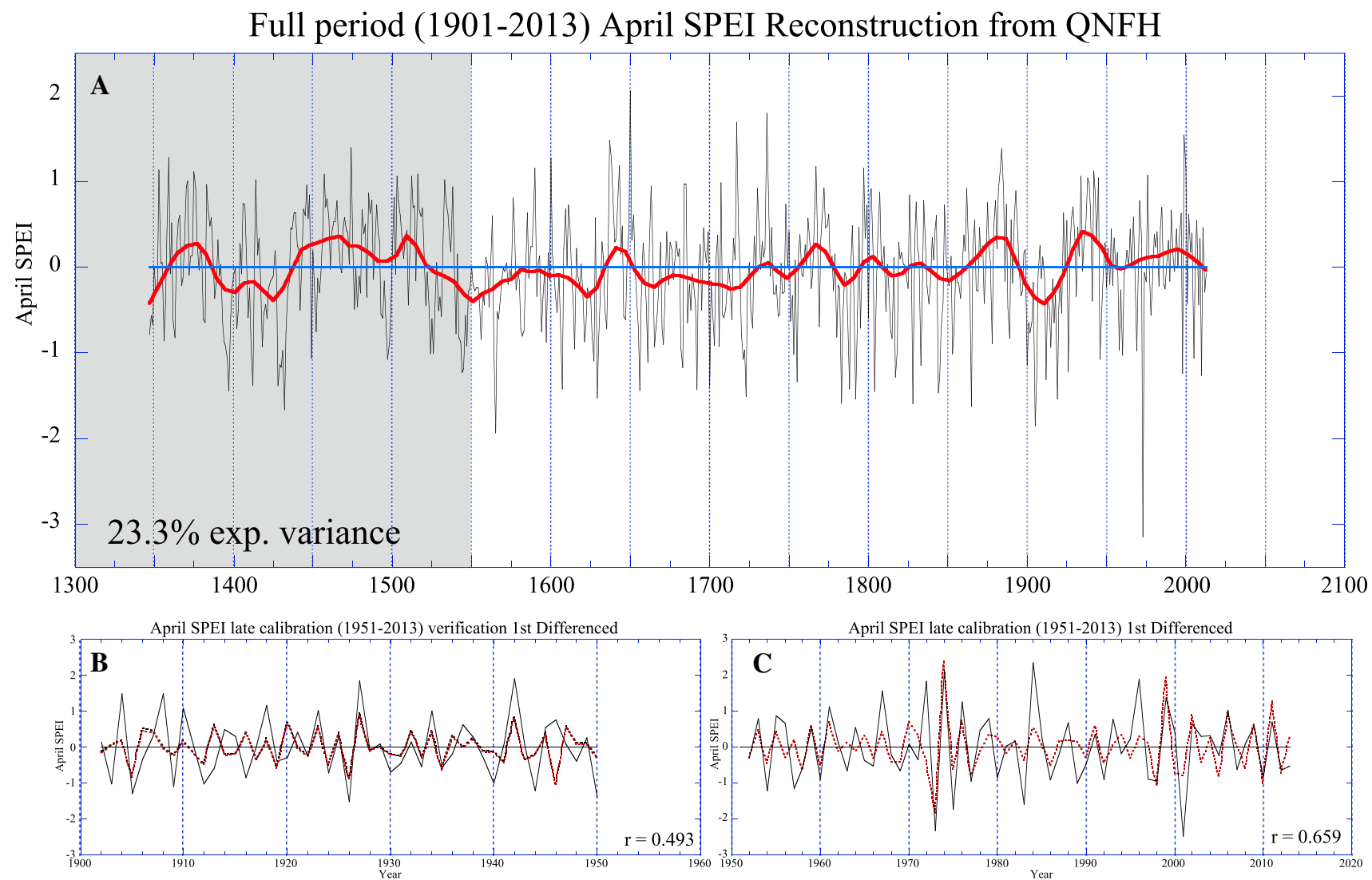

Fig. 9 The full-period tree-ring based reconstruction of April SPEI (a) for an average of the two boxes of gridded values as shown in Fig. 7. The full reconstruction explains $23.3 \%$ of the variance in the original SPEI data and passes all calibration-verification tests as shown in Table 3. Calibration on the outer half of the record (1951-
2013) for first differenced data shows the very strong relationship between actual and estimated values of April SPEI, as shown in $\mathbf{c}$ for the calibration period and $\mathbf{b}$ for the verification period (1901-1950) estimates (black and red dashed lines for robust and raw estimates for $\mathbf{b}$, and red dashed lines for $\mathbf{c}$ and solid line for actual values
(Shaman and Tziperman 2005). The 850-hPa height and SLP anomalies depict the broad La Niña features in the Pacific such as the strengthened trade winds, and also highlights a local cyclonic cell over and to the west of Indochina. This local circulation appears to be connected with negative anomalies of SST in the Indian Ocean, of which the pattern has been identified as the Indian Ocean Basin Mode (IOBM; Yang et al. 2007). It is worth noting that IOBM is not just a passive response to El Niño, and its negative anomaly during April-May can induce a similar atmospheric circulation pattern to the one shown in Fig. 11.

The out-of-phase relationship and shared decadal spectral coherence between the EP-NP index and autumn precipitation in central Vietnam as presented by $\mathrm{Li}$ et al. (2015) may explain an apparent reduction in the severity of the eighteenth century megadrought at QNFH relative to north and south regions of Vietnam. This inference was derived from the fact that historical severe droughts are mostly multi-year events that are tied to decadal-scale variability. At the interannual scale, Chen et al. (2013) describe another linkage between the winter months climatology on a broader scale with the following year's summer monsoon, and distinguish between years when the East Asian Winter Monsoon (EAWM) is modulated by the effects of ENSO $\left(\mathrm{EAWM}_{\mathrm{EN}}\right)$ and those that are not. They demonstrate that a strong (weak) $\mathrm{EAWM}_{\mathrm{EN}}$ leads to a weak (strong) summer monsoon in the following pre-monsoon months of MarchMay over a broad swath of Asia that includes our study region. This relationship is also modulated by the strength of the decadal variability that is present in both the Pacific and Indian Oceans (Chen et al. 2013). 


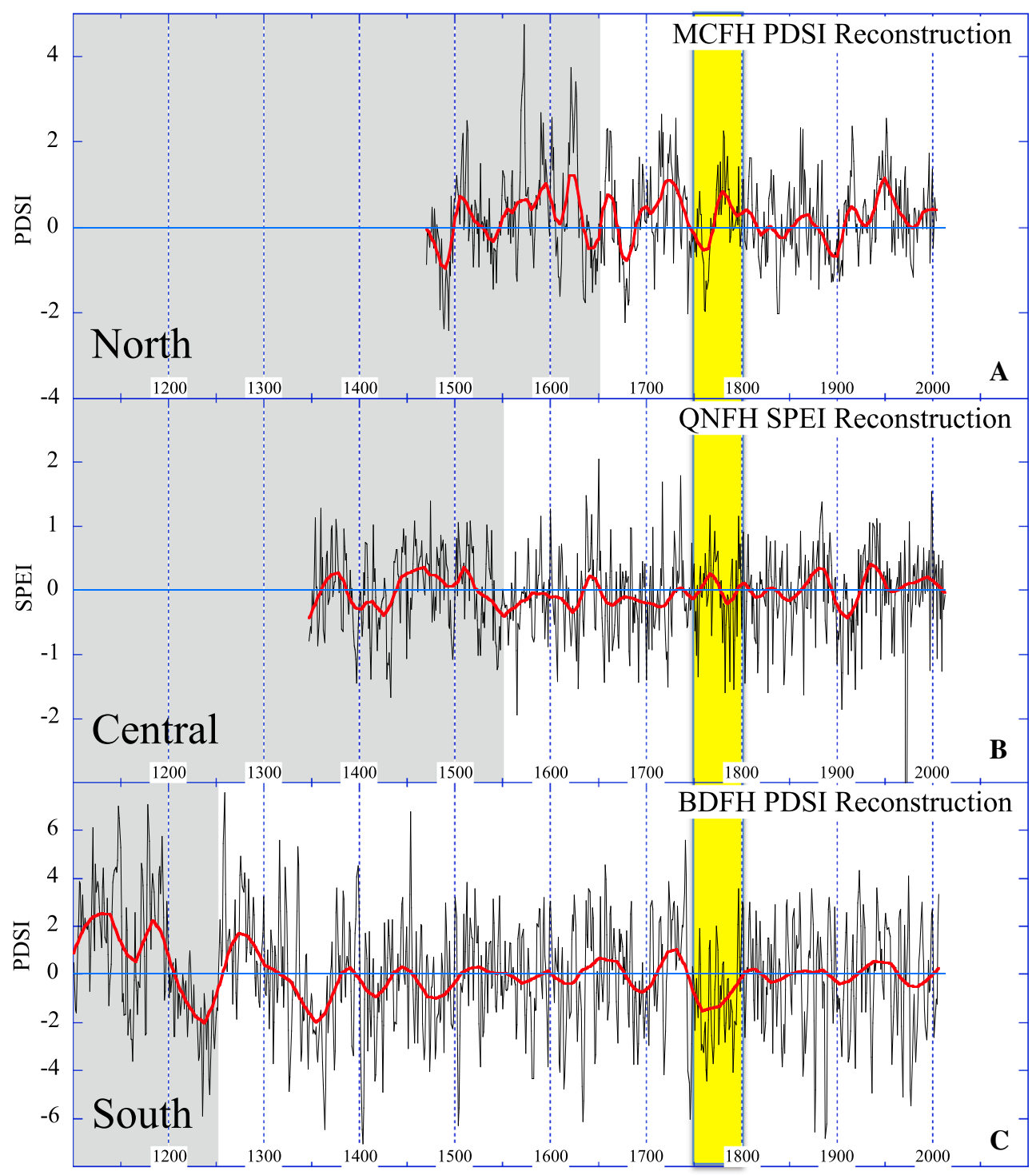

Fig. 10 The three Vietnam tree ring climate reconstructions from a Mu Cang Chai in the north, b Quang Nam in the center, and c Bidoup-Nui Ba National Park in the south of Vietnam. The gray boxes denote the portion of the record where the EPS statistic falls below the generally accepted threshold of 0.85 (Wigley et al. 1984), from A.D. 1650 for MCFH, 1550 for QNFH and 1250 for BDFH.

Under the inference of the aforementioned largescale atmospheric anomalies, the regional response in climate can be seen from the strong inverse relationship between April SPEI and maximum temperature over Indochina (Fig. 12). An increase in early season
The yellow bar highlights the latter half of the eighteenth century, a period marked by general conditions of drought in the north and south of Vietnam as discussed by Sano et al. (2009) and Buckley et al. (2010, 2014), respectively. The severity of decadal scale drought during this period appears to be minimized in central Vietnam as expressed in the QNFH record

moisture and cloudiness that would accompany this increased onshore flow ought surely play a role in keeping plants hydrated and cool enough through atmospheric vapor pressure to mitigate the effects of drought. It is clear that the large-scale dynamics of climate play 

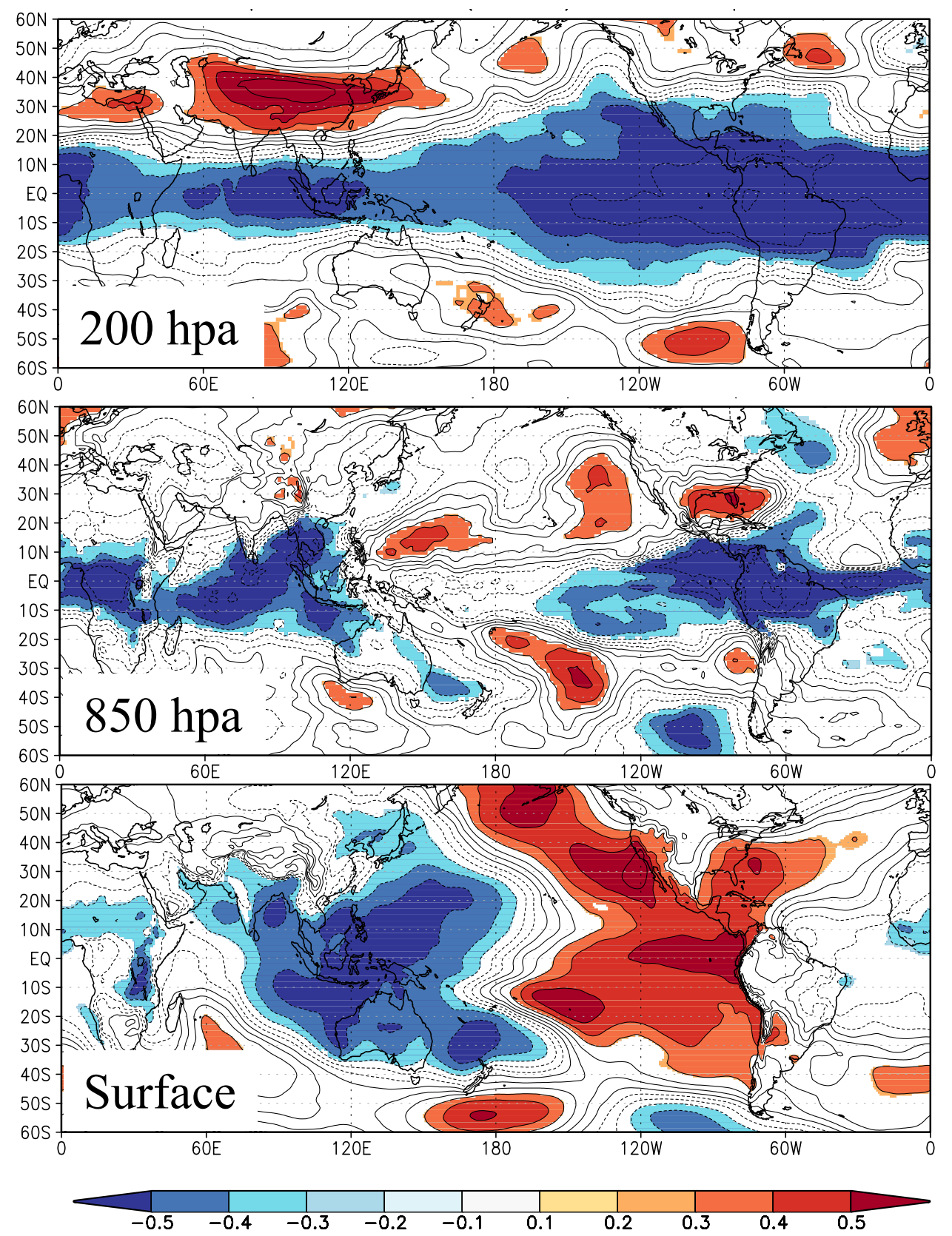

Fig. 11 The center and top plots show the correlation between our April SPEI reconstruction and temperature for April at the 850 and 200 hpa heights, respectively, and against Sea Level Pressure at the surface for the 6 months from prior November to current April in the bottom plot. Taken together these plots reflect the coupled oceanic- atmospheric linkages between climate over the study region, global circulation and ENSO. All data were detrended prior to correlation for the time period of 1979-2013. Source ERA-interim data from the European Center for Medium-Range Weather Forecasting

hodginsii's ecophysiological response to climate (i.e., water, temperature and light) would be an important additional step toward better understanding the results of the current research. 
Fig. 12 Reconstructed April SPEI against maximum temperature (Tmax) for MarchMay for the period 1950-2013 (temperature data from the CRU TS3.22 dataset from the Climate Research Unit at the University of East Anglia in the U.K.). All data were detrended prior to correlation

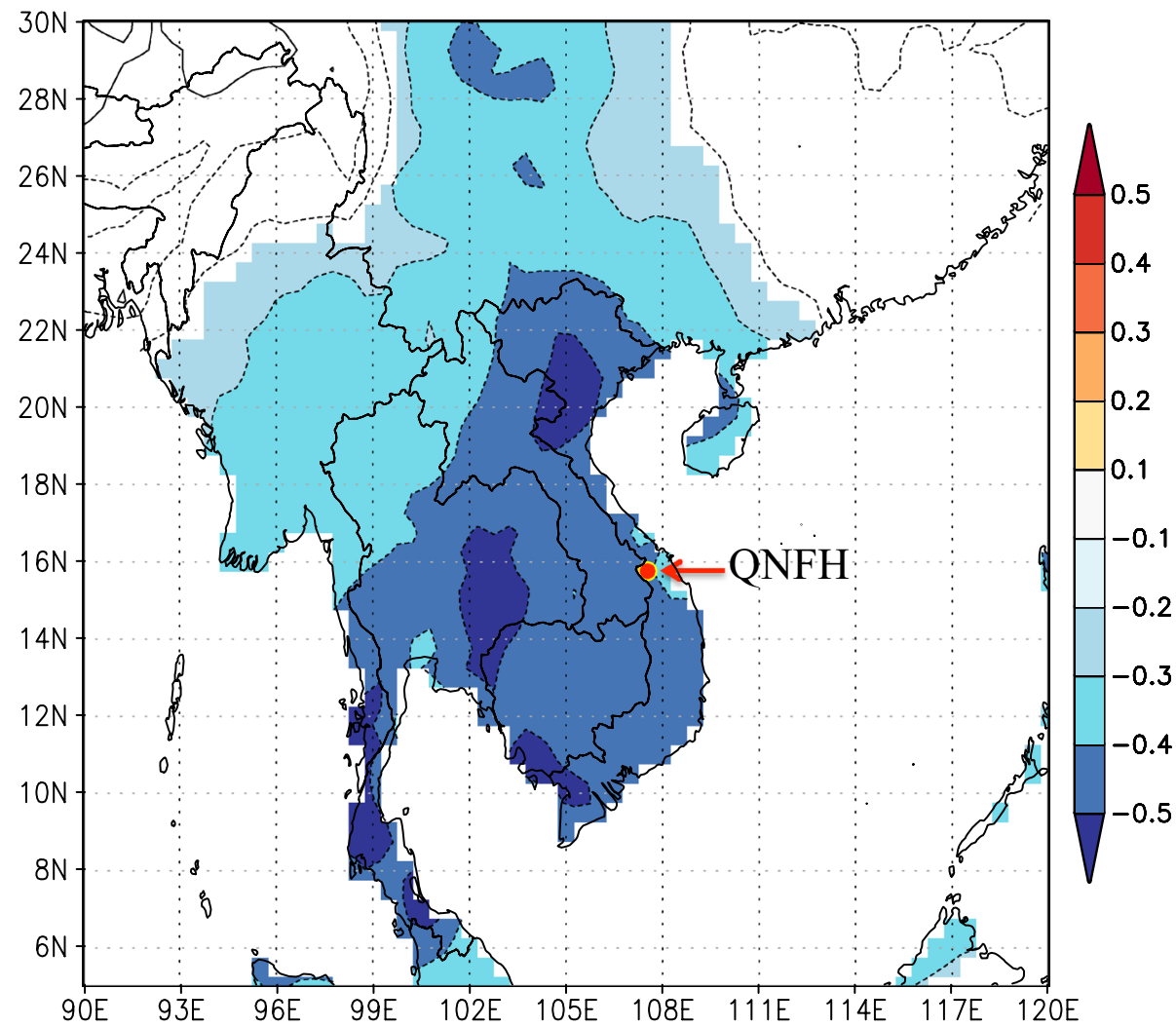

\section{Conclusions}

This study presents the first tree ring record collected from the mountainous region of central Vietnam and the first climate reconstruction of SPEI for the region-one that passes the rigorous calibration-verification tests commonly used in dendroclimatology. The climate of central Vietnam is distinctly different from the rest of the country in that autumn rainfall is a significant contributor to the annual rainfall totals, more so than the summer monsoon that dominates the rainfall regimes of northern and southern Vietnam, respectively. The mechanism for this is found within the coupled ocean-atmosphere dynamics of the sea to the east of Vietnam and across the global tropics, particularly in the tropospheric circulations. The thermal gradient between the Asian high mountains (the Tibetan Plateau) and the equatorial ocean, notably in the areas closely linked with the ENSO phenomenon, apparently modulates the hydroclimate over Indochina as well. The additional influence of the Northeastern winter monsoon over central Vietnam specifically, and broadly across mainland Southeast Asia during times of strong ENSO and decadal modulation, may provide an important counterbalance to soil moisture deficits generated during particularly severe droughts from the annual dry season. Concurrent SST variations in the Indian Ocean also play a role, and a further connection to increased tropical cyclonic activity during the autumn peak of rainfall may serve to mitigate (or worsen) any spring drought over central Vietnam.

Since the tree ring record and its SPEI reconstruction is the first produced from central Vietnam, more detailed research is needed, particularly with regard to the role of local topography on climate at this site. A deeper, more mechanistic understanding of the physiological controls on the growth of Fokienia hodginsii with regard to hydroclimate is also needed. In addition, the role of any possible changes in the coupled ocean-atmospheric system over the past millennium needs to be considered in interpreting changes in the regional hydroclimate.

Acknowledgments This research was conducted with the support of the US National Science Foundation Grants AGS 12-03818 and AGS 13-03976 and of the Vietnam Academy of Science and Technology Grant VAST.HTQT.HOAKY.01/12. The Royal Botanic Garden Edinburgh is funded by the Rural and Environment Science and Analytical Services division (RESAS) in the Scottish Government. The authors wish to thank the managers and staff from the Quang Nam Province and Tay Giang District, especially Mr. Phan Tuan, Mr. Briu Liec and Mr. Bhling Mia, for all of their support and cooperation. The local Co Tu villagers are thanked for their kindness, good cheer and their assistance with the fieldwork. We also thank the staff and directorship of Bidoup - Nui Ba National Park in Lam Dong Province and the Southern Institute of Ecology in HCMC for logistical help, and acknowledge the Lamont-Doherty Earth Observatory's Climate and Life Initiative as well as the Lamont-Doherty Climate Center for their 
support. We thank Dr. Edward Cook for his review of, and comments on, our section about the SFS method. Lamont-Doherty Contribution No. 8031 .

\section{References}

Anchukaitis KJ, Buckley BM, Cook ER, Cook BI, D'Arrigo RD, Ammann CM (2010) The influence of volcanic eruptions on the climate of the Asian monsoon region. Geophys Res Lett 37:L22703. doi:10.1029/2010GL044843

Baker PJ, Bunyavejchewin S, Oliver CD, Ashton PS (2005) Disturbance history and historical stand dynamics of a seasonal tropical forest in western Thailand. Ecol Monogr 75(3):317-343

Beguería S, Vicente-Serrano SM, Reig F, Latorre B (2014) Standardized precipitation evapotranspiration index (SPEI) revisited: parameter fitting, evapotranspiration models, tools, datasets and drought monitoring. Int J Climatol 34(10):3001-3023

Black BA, Griffin D, Van der Sleen P, Wanamaker AD, Speer JH, Frank DC, Stahle DW, Pederson N, Copenheaver CA, Trouet V, Griffin S (2016) The value of crossdating to retain high-frequency variability, climate signals and extreme events in environmental proxies. Glob Change Biol. doi:10.1111/gcb.13256

Briffa KR, Melvin TM (2011) A closer look at regional curve standardization of tree-ring records: justification of the need, a warning of some pitfalls, and suggested improvements in its application. In: Hughes MK et al (eds) Dendroclimatology. Springer, Netherlands, pp 113-145

Buckley BM, Barbetti M, Watanasak M, D'Arrigo RD, Boonchirdchoo S, Sarutanon S (1995) Dendrochronological investigations in Thailand. IAWA J 16(4):393-409

Buckley BM, Cook BI, Bhattacharyya A, Dukpa D, Chaudhary V (2005) Global surface temperature signals in pine ring width chronologies from southern monsoon Asia. Geophys Res Lett 32:L20704

Buckley BM, Duangsathaporn K, Palakit K, Butler S, Syhapanya V, Xaybouangeun N (2007a) Analyses of growth rings of Pinus merkusii from Lao PDR. For Ecol Manag 253(1-3):120-127

Buckley BM, Palakit K, Duangsathaporn K, Sanguantham P, Prasomsin P (2007b) Decadal scale droughts over northwestern Thailand over the past 448 years: links to the tropical Pacific and Indian Ocean sectors. Clim Dyn 29(1):63-71

Buckley BM, Anchukaitis KJ, Penny D, Fletcher RC, Cook ER, Sano M, Le CN, Wichienkeeo A, Ton TM, Truong MH (2010) Climate as a contributing factor in the demise of Angkor, Cambodia. Proc Natl Acad Sci 107(15):6748

Buckley BM, Fletcher RC, Wang S-Y, Zottoli B, Pottier C (2014) Monsoon Extremes and Society over the past millennium on mainland Southeast Asia. Quat Sci Rev. doi:10.1016/j. quascirev.2014.04.022

Chen M, Xie P, Janowiak JE, Arkin PA (2002) Global land precipitation: a 50-year monthly analysis based on gauge observations. J Hydrometeorol 3(3):249-266

Chen W, Feng J, Wu R (2013) Roles of ENSO and PDO in the link of the East Asian winter monsoon to the following summer monsoon. J Clim 26(2):622-635

Cook ER, Kairiukstis LA (eds) (1990) Methods of dendrochronology: applications in the environmental sciences. Kluwer Academic Publishers, Dordrecht, Boston, London

Cook ER, Anchukaitis KJ, Buckley BM, D'Arrigo RD, Wright WE, Jacoby GC (2010) Asian monsoon failure and megadrought during the last Millennium. Science 328(5977):486-489. doi:10.1126/science. 1185188

D'Arrigo RD, Palmer J, Ummenhofer CC, Kyaw NN, Krusic P (2011) Three centuries of Myanmar monsoon climate variability inferred from teak tree rings. Geophys Res Lett 38:L24705. doi: 10.1029/2011GL049927

Dai A, Trenberth K, Qian T (2004) A global data set of Palmer Drought Severity Index for 1870-2002: relationship with soil moisture and effects of surface warming. J Hydrometeorol 5:1117-1130. doi:10.1175/JHM-386.1

D’Arrigo RD, Barbetti M, Watanasak M, Buckley BM, Krusic P, Boonchirdchoo S, Sarutanon S (1997) Progress in dendroclimatic studies of mountain pine in northern Thailand. IAWA J 18(4):433-444

Davis M (2002) Late Victorian holocausts: El Niño famines and the making of the third world. Verso, London, p 529

Fritts HC (1976) Tree rings and climate. Academic Press, San Diego, CA

Fritts HC, Swetnam TW (1989) Dendroecology: a tool for evaluating variations in past and present forest environments. Adv Ecol Res 19:111-188. doi:10.1016/S0065-2504(08)60158-0

Ho TMH, Phan VT, Le NQ, Nguyen QT (2011) Extreme climatic events over Vietnam from observational data and RegCM3 projections. Clim Res 49:87-100. doi:10.3354/cr01021

Li R, Wang S-Y, Gillies RR, Buckley BM, Luu HT, Cho C (2015) Decadal oscillation of autumn precipitation in central Vietnam modulated by the East Pacific-North Pacific (EP-NP) teleconnection. Environ Res Lett 10:024008. doi:10.1088/1748-9326/10/2/024008

McElwee PD (2012) Payments for environmental services as neoliberal market-based forest conservation in Vietnam: Panacea or problem? Geoforum 43(3):412-426

Melvin TM, Briffa KR (2008) A "signal-free" approach to dendroclimatic standardisation. Dendrochronologia 26(2):71-86

Melvin TM, Briffa KR (2014) CRUST: software for the implementation of Regional Chronology Standardisation: Part 1. Signal-Free RCS. Dendrochronologia 32(1):7-20

Palmer WC (1965) Meteorological drought, vol 30. US Department of Commerce, Weather Bureau Research Paper No. 45, Washington, DC, USA

Pumijumnong N, Eckstein D (2011) Reconstruction of pre-monsoon weather conditions in northwestern Thailand from the tree-ring widths of Pinus merkusii and Pinus kesiya. Trees 25(1):125-132

Pumijumnong N, Wanyaphet T (2006) Seasonal cambial activity and tree-ring formation of Pinus merkusii and Pinus kesiya in Northern Thailand in dependence on climate. For Ecol Manag 226(1):279-289

Pumijumnong N, Eckstein D, Sass U (1995) Tree-ring research on Tectona grandis in northern Thailand. IAWA J 16(4):385-392

Räsänen TA, Lindgren V, Guillaume JHA, Buckley BM, Kummu M (2015) On the spatial and temporal variability of ENSO precipitation and drought teleconnection in mainland Southeast Asia. Clim Past Discuss 11:5307-5343. doi:10.5194/ cpd-11-5307-2015

Sano M, Buckley BM, Sweda T (2009) Tree-ring based hydroclimate reconstruction over northwest Vietnam from Fokienia hodginsii: eighteenth century megadrought and tropical Pacific influence. Clim Dyn 33(2):331-340

Sano M, Xu C, Nakatsuka T (2012) A 300-year Vietnam hydroclimate and ENSO variability record reconstructed from tree ring $\mathrm{d} 18 \mathrm{O}$. J Geophys Res 117(D12):D12115

Shaman J, Tziperman E (2005) The effect of ENSO on Tibetan Plateau snow depth: a stationary wave teleconnection mechanism and implications for the South Asian monsoons. J Clim 18(12):2067-2079

Stahle DW, Diaz JV, Burnette DJ, Paredes J, Heim RR, Fye FK, Acuna Soto R, Therrell MD, Cleaveland MK, Stahle DK (2011) Major Mesoamerican droughts of the past millennium. Geophys Res Lett 38(5):L05703 
Stahle DW, Burnette DJ, Diaz JV, Heim RR Jr, Fye FK, Paredes JC, Soto RA, Cleaveland MK (2012) Pacific and Atlantic influences on Mesoamerican climate over the past millennium. Clim Dyn 39(6): 1431-1446

Stokes MA, Smiley TL (1968) Tree-ring dating. Tree-ring dating. University of Arizona Press

Therrell MD, Stahle DW, Ries LP, Shugart HH (2006) Tree-ring reconstructed rainfall variability in Zimbabwe. Clim Dyn 26(7-8):677-685

Trouet V, Van Oldenborgh GJ (2013) KNMI Climate Explorer: a webbased research tool for high-resolution paleoclimatology. Tree Ring Res 69(1):3-13

Vicente-Serrano SM, Beguería S, López-Moreno JI (2010) A multiscalar drought index sensitive to global warming: the standardized precipitation evapotranspiration index. J Clim 23(7):1696-1718

Vicente-Serrano SM, Gouveia C, Camarero JJ, Beguería S, Trigo R, López-Moreno JI, Azorín-Molina C, Pasho E, Lorenzo-Lacruz J, Revuelto J, Morán-Tejeda E (2013) Response of vegetation to drought time-scales across global land biomes. Proc Natl Acad Sci 110(1):52-57
Wang S-Y, Promchote P, Luu HT, Buckley BM, Li R, Gillies R, Nguyen TQT, Guan B, Ton TM (2015) Changes in the autumn precipitation and tropical cyclone activity over Central Vietnam and its East Sea. Vietnam J Earth Sci 36: 489-496. http://cliserv. jql.usu.edu/paper/VN_White_Paper_proof.pdf

Wigley TM, Briffa KR, Jones PD (1984) On the average value of correlated time series, with applications in dendroclimatology and hydrometeorology. J Clim Appl Meteorol 23(2):201-213

Xu C, Sano M, Nakatsuka T (2011) Tree ring cellulose d18O of Fokienia hodginsii in northwest Laos: a promising proxy to reconstruct ENSO? J Geophys Res 116(D24):D24109

Yang J, Liu Q, Xie SP, Liu Z, Wu L (2007) Impact of the Indian Ocean SST basin mode on the Asian summer monsoon. Geophys Res Lett 34:L02708

Zuidema PA, Baker PJ, Groenendijk P, Schippers P, van der Sleen P, Vlam M, Sterck F (2013) Tropical forests and global change: filling knowledge gaps. Trends Plant Sci 18(8):413-419 